\title{
Las colecciones de textiles andinos en los museos de España
}

\section{RESUMEN}

Este trabajo trata de ofrecer una visión actualizada de las colecciones de textiles andinos de los principales museos públicos de España. Se hablará de su procedencia, de cómo se formaron las colecciones y se hará hincapié en los textiles más interesantes de cada una de ellas. Se deberá tener en cuenta que la mayoría de piezas textiles llegaron a los museos por compra o por donación, y que lamentablemente carecen de contexto en su mayoría.

Palabras claves: museos públicos de España - colecciones textiles precolombinas - textiles andinos.

\section{ABSTRACT}

This work aims to provide an updated outlook of the Andean textile collections in the main Spanish public museums. The origin of these collections will be addressed, as well as the way in which they were constituted, and the main items of each one of them will be reviewed. It is essential to stress that most of the textiles reached the museums by purchase or donation, so unfortunately they lack archaeological context.

Key words: Spanish public museums - Pre-columbian textile collections - Andean textiles.

\section{Introducción}

A efectos de estudio, presentaremos a los museos públicos de España en tres apartados de acuerdo al número de piezas que poseen: un primer apartado lo constituye el Museo de América de Madrid; el segundo corresponde a los tres museos de Barcelona (ciudad y provincia) que poseen más piezas; y el tercer apartado lo constituyen una serie de museos locales que tienen un número menor de piezas.

Las piezas del Museo de América de Madrid (MAM) -institución que posee el mayor número

1 Departamento de Arte, Facultad de Letras, Universidad Autónoma de Barcelona. 08193 Bellaterra, España. Email: Victoria.Solanilla@uab.es de ejemplares-, proceden de la Expedición del Pacífico y de las colecciones Larco Herrera, Schmidt Pizarro, Juan Larrea, y Juan Caballero, cuya mayoría ha podido ser identificada y catalogada y ha sido y es motivo de estudio.

Los museos Etnológico (MEB) y el Textil y de Indumentaria (MTIB) de Barcelona, y el Museo Textil de Terrassa (CDMT), también poseen colecciones interesantes, pero menos numerosas que la anteriormente citada, que también han sido recientemente motivo de estudio y catalogación.

Por último, en el apartado de los museos locales que poseen pequeñas colecciones en cuanto a número pero no en cuanto a su interés, se agrupan el Museo Episcopal de Vic, el Museo Darder de Historia Natural de Banyoles, el Museo Víctor Balaguer de Vilanova i la Geltrú, y el Museo Barbier Mueller de Barcelona. Todas sus piezas han sido también objeto de catalogación.

\section{Museo de América de Madrid}

El Museo de América de Madrid tiene su origen en un Decreto del año 1941, abriendo sus puertas en su sede actual en 1965. En 1981 el museo se cerró para completar las obras pendientes y acabar las partes no terminadas del edificio, adaptando aquellas que estaban ocupadas por otras instituciones. Se abrió definitivamente al público en 1994, después de haber ordenado, catalogado e investigado sus fondos, que se publicaron y exhibieron en numerosas exposiciones temporales. Se procedió a su estructuración por temas monográficos que mostrarían la compleja realidad americana. Es el producto de la fusión de diversas colecciones adquiridas en diferentes siglos. Estos aspectos están documentados por Paz Cabello (1989) en su libro sobre coleccionismo americanista, y en la guía del museo que ha publicado la misma autora (1994).

La base de sus fondos museísticos tiene su origen en el Real Gabinete de Historia Natural del siglo XVIII. A partir de 1867 pasaron al Museo Ar- 
queológico, integrando la Sección IV o de Etnografía, que se incrementaría en años posteriores. Durante el siglo XIX tuvo lugar la Expedición del Pacífico y las exposiciones americanas del Congreso Americanista (1881) y de la conmemoración del IV Centenario del Descubrimiento de América (1892). Estos acontecimientos hicieron aumentar el interés por el estudio y acopio de nuevas colecciones. Durante la primera mitad del siglo XX se realizaron nuevas compras: la Colección Schmidt y Pizarro (1930) y la Colección Caballero, algo posterior (1968), y dos importantes donaciones: la Colección Larco Herrera (1920), integrada por objetos de la Costa Norte del Perú, y la Colección Juan Larrea (1936), compuesta por objetos incas.

La existencia de textiles entre estos fondos, que en la actualidad pueden ser definidos como colecciones fundacionales, queda reflejada en descripciones antiguas y reseñas de listas de envío de materiales al Gabinete de Historia Natural, entre ellas las de las expediciones científicas del siglo XVIII, así como en las primeras relaciones de materiales que contenía el mismo, y en el Libro Inventario redactado por Florencio Janer en 1860.

Como ponen de manifiesto Ramos y Blasco (1980: 49), la pobreza descriptiva de datos y la ausencia de referencias relativas al lugar de procedencia y a cuándo, por quién y cómo fueron adquiridos puesto se trata de objetos recopilados principalmente como curiosidad- hacen en general imposible la identificación de los tejidos basándose en esas referencias.

Hay que tener en cuenta, además, que muchas de las descripciones que se encuentran en los inventarios antiguos se refieren a piezas que han desaparecido a lo largo del tiempo, o de las que sólo quedan fragmentos, dada la fragilidad de sus materiales o a causa de los daños sufridos como consecuencia de sus sucesivos traslados, o de exposiciones y sistemas de almacenaje inadecuados. Ecija y Verde (2000: 57) cuentan que a esta pérdida física también ha contribuido la ausencia de estudios y contextualización cultural y cronológica de las mismas, tanto por falta de métodos científicos como por el desconocimiento de la existencia de las respectivas culturas arqueológicas. Poco a poco han ido desapareciendo las etiquetas de las piezas -si las había- sobre su adquisición o procedencia, hecho que incide en que las colecciones hayan perdido su documentación, y por tanto, su valor de colección como conjunto.

Los únicos tejidos estudiados (136), documentados y publicados son los presentados por Ramos y Blasco (1980). También hay otros autores que han publicado con menos detalle algunas piezas que se corresponden con los mismos tejidos. Entre ellos, Mariano Cuesta (1980), publicó en su catálogo del mundo andino una serie de textiles de los que da tan sólo una cronología relativa.

Con posterioridad o simultáneamente a estos trabajos, Flor Portillo estudió unos determinados tejidos de número desconocido para la realización de su tesis doctoral, que malogradamente quedó sin publicar (Ecija y Verde 2000: 58). Lo mismo ha sucedido con los estudiados por Markus Reindel al realizar su tesis doctoral sobre 128 textiles, que, sin embargo, no presentan una relación fiable puesto que varias piezas están sigladas con el mismo número, y además, tres de las piezas estudiadas no se han podido encontrar hasta ahora (Ecija y Verde 2000: 58).

En 1998, María Jesús Jiménez estudió una selección de 35 tejidos, recientemente publicados (Jiménez 2001) de los que sólo dos no se encuentran en el catálogo de Ramos y Blasco (1980). Centró su trabajo en la contextualización cultural y en la importancia socioeconómica de los textiles dentro de las relaciones comerciales entre los diferentes pueblos de la costa.

Con motivo de la "I Jornada Internacional sobre Textiles Precolombinos" que se celebró en Barcelona en noviembre de 1999, Ecija y Verde presentaron una comunicación sobre la colección de textiles andinos precolombinos y coloniales del MAM (Ecija y Verde 2000: 57-65) en la que revisaron toda la historia de la formación de sus diversas colecciones textiles desde sus inicios hasta el momento actual, llevando a cabo un trabajo de búsqueda, siglado y documentación general de todas las piezas.

Con anterioridad a esa documentación, se ha realizado en estos últimos años una labor importante de restauración para que fuera efectiva la conservación y mantenimiento de esos textiles. Dado que la mayor parte de estas piezas proceden de ajuares funerarios de momias, presentan manchas de materia orgánica y suciedad propias de los enterramientos. Este hecho, junto con los inadecuados sistemas de almacenaje que han sufrido, han pro- 
ducido deformaciones, decoloraciones, roturas y pérdidas de fibras.

Para tratar de solventar todos estos problemas, los textiles han sido colocados en soportes adecuados (blandos o rígidos), se han limpiado y fijado los hilos, y finalmente se ha dado el volumen que reclaman las piezas mediante diferentes medios técnicos, cuando ha sido necesario.

Actualmente, estos textiles se encuentran guardados sobre sus soportes en planeros metálicos de cierre hermético que impiden la filtración de luz y polvo, y los depósitos se han acondicionado en cuanto a temperatura (entre $18^{\circ} \mathrm{C}$ y $23^{\circ} \mathrm{C}$ ), luz (ausencia de la misma, salvo cuando se requiere para entrar en el depósito) y humedad (relativa del $40 \%$ ).

Se trata de una colección formada por 317 tejidos (309 prehispánicos y 8 coloniales), representativa del Area Andina tanto desde el punto de vista de las técnicas como de sus etapas cronológicas y culturales. La mayor parte de ellos pertenece al Período Intermedio Tardío, aunque también están representados todos los períodos cronológicos establecidos para la arqueología del área. La mayoría son fragmentos, en algunos casos muy deteriorados, pero también se pueden apreciar ejemplares muy significativos y piezas completas (túnicas, fajas, cintas, gorros, bolsas, muñecas, balanzas, pulseras, hondas, madejas y ovillos).

De entre estas piezas destacan las que se describen a continuación: unas piezas de época Nazca que consisten en dos fragmentos de bordes de túnicas ( $n^{\circ}$ Inv. 14516 y 14641), con una decoración en forma de greca en ' $S$ ' y fleco, documentadas por varios autores (D'Harcourt 1962: plate 86, Ramos y Blasco 1980: 68-69, lám. IX fig. G, Jiménez 2000: 227), hechos con técnica de tejido a la aguja y en una gama amplia de tonos (Figura 1). También hay otra pieza poco común ( $n^{\circ}$ Inv. 14525) cuya decoración consta de dos motivos diferentes: un ave con pico, alas, cola y garras de grandes dimensiones; y una cabeza cuadrangular de la que salen cuatro apéndices terminados por cabezas, hecha con técnica de tapiz propia de la tradición serrana. Ramos y Blasco (1980:82, lám. XIII, fig. C) la han atribuido al Horizonte Medio y posteriormente, en un estudio muy bien realizado, Jiménez (2000: 228-232, fig. 1), la ha insertado dentro del estilo Recuay (Figura 2).

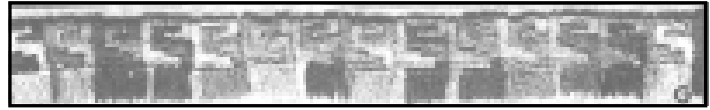

Figura 1. MAM 14516-1464.

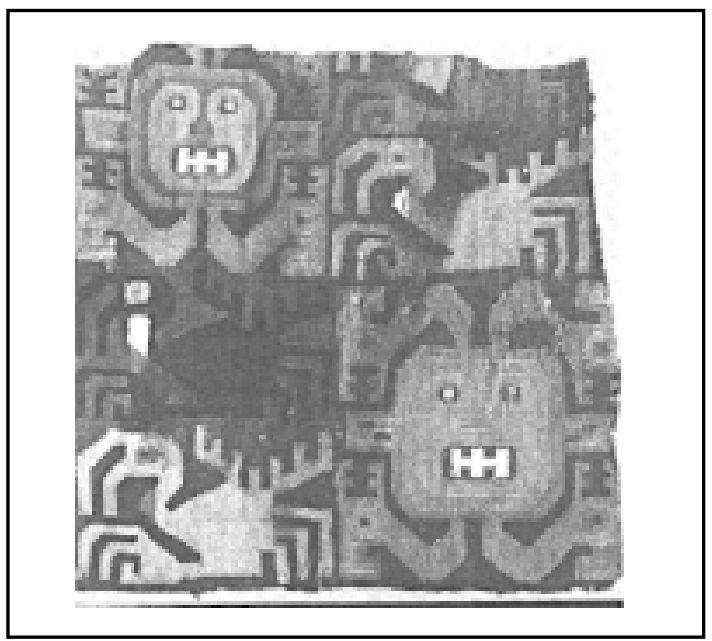

Figura 2. MAM 14525.

También del Horizonte Medio hay una pieza ( $\mathrm{n}^{\mathrm{o}}$ Inv. 14522) procedente de la Costa Sur y con una decoración de figuras antropomorfas y zoomorfas, colocadas en cuadrados alternándose cromáticamente en ejes diagonales (Jiménez 2000: 235, fig. 5) que tiene un claro paralelo, tanto de decoración como de técnica (Figura 3), en una pieza que se conserva en el CDMT (Solanilla 1999: 142143, fig. 77) y que se atribuyó a la Cultura Chancay porque procedía de la Costa Central y así constaba en el registro del museo.

Otro ejemplar con paralelos es un fragmento de tapiz kilim o de ranuras ( $\mathrm{n}^{\circ}$ Inv. 14566) (Ramos y

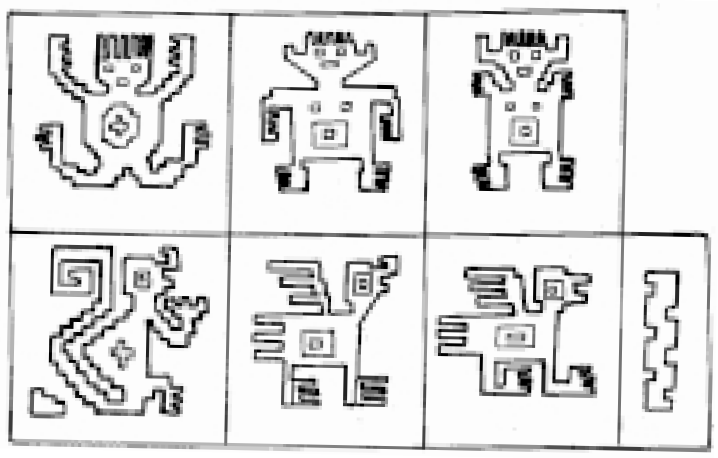

Figura 3. MAM 14522. Siete motivos que conforman la decoración de este tejido colocados en 38 cuadros. 
Blasco 1980: 116-118, lám. XXII, Jiménez 2000: 239-242, fig. 7) decorado con cinco personajes iguales dentro de cuadrados en horizontal, ricamente vestidos con un báculo en una mano y una cabeza-trofeo en la otra; a su alrededor se observan otros pequeños motivos como llamas y pequeños portadores de báculos (Figura 4). Su paralelo está en el Museo Arqueológico de Cracovia (Solanilla 2000: 72-73): en este caso el personaje lleva un báculo en cada mano y coinciden claramente en indumentaria, técnica y colores. Esta pieza la situamos al final del Horizonte Medio.

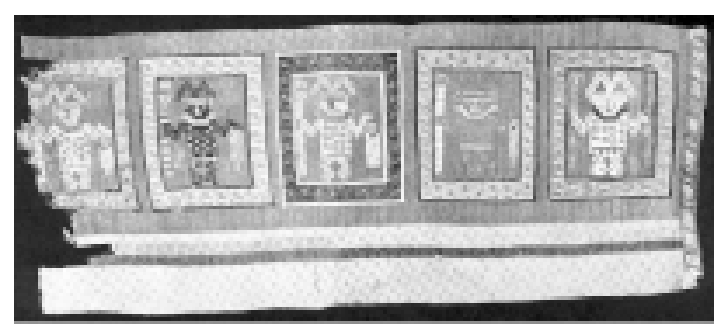

Figura 4. MAM 14566.

Hay muchas piezas del Período Intermedio Tardío, como suele ocurrir en todos los museos del mundo. Destacamos los textiles Chimú y Chancay, porque llegaron a un alto nivel de calidad y se extendieron ampliamente por la Costa Norte y Central, y de entre ellos un fragmento de túnica ( ${ }^{\circ}$ Inv. 14571; Ramos y Blasco 1980: 122-123, lám. XXIV, fig. B y Jiménez 2000: 248-249, fig. 9) rematado con flecos, con técnica de tapicería y decorado con dos hileras de personajes ataviados con tocado diferente en cada una de ellas (Figura 5). Su paralelo idéntico está en el MTIB en cuanto a elaboración, decoración y medidas (Solanilla 1999: 114-115, fig. 53); pero, como advierte Jiménez, los hilos de la urdimbre parece ser que estaban hilados y torcidos de manera opuesta a los del MAM.

Finalmente, del Horizonte Tardío destacamos una pieza excepcional ( $\mathrm{n}^{\circ}$ Inv. 14636) de medida im-

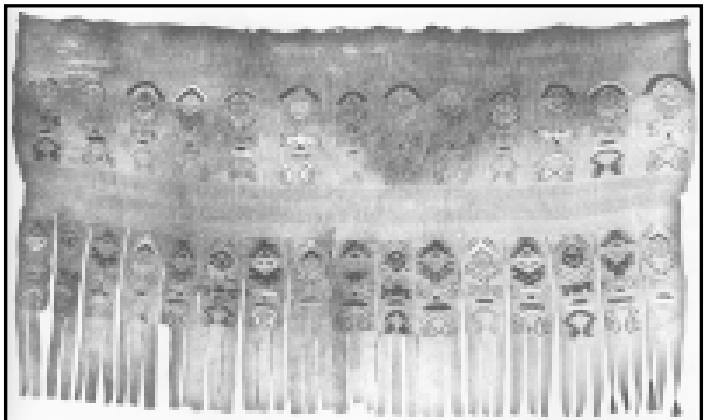

Figura 5. MAM 14571.

portante $(124 \mathrm{~cm} \times 21 \mathrm{~cm})$ que es un tejido decorado por tocapus hecho con técnica de reps, completo en sentido de la trama y recortado en la urdimbre (Figura 6). De gran colorido, procedía del Cuzco (Ramos y Blasco 1980: 186-189, lám. XLII, fig. C y lám. XLIV, fig. B). Y también una túnica o uncu completo ( $\mathrm{n}^{\circ}$ Inv. 14501), decorado con cuatro rectángulos de color diferente que contienen cantutas o fucsias, enmarcados en el centro

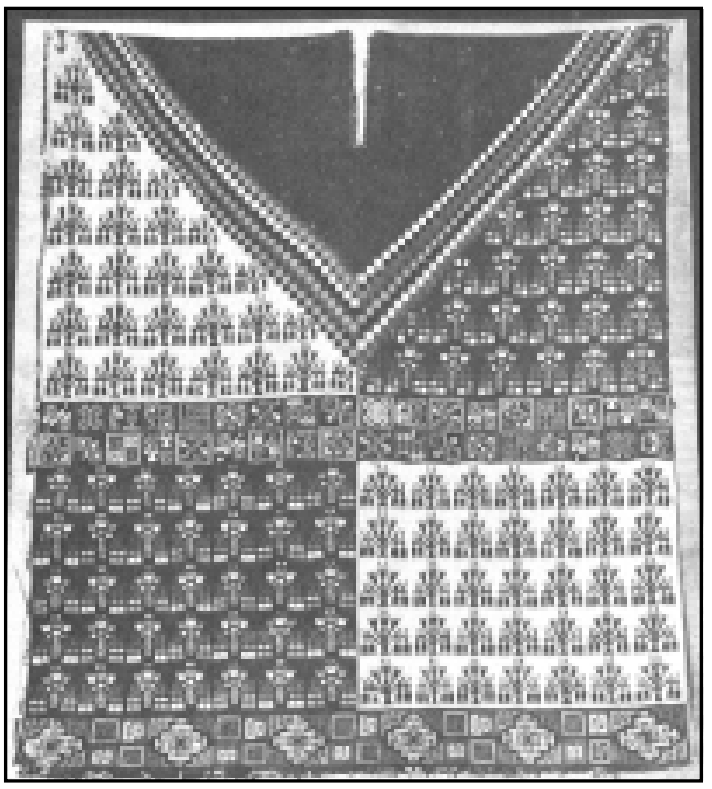

Figura 7. MAM 14501.

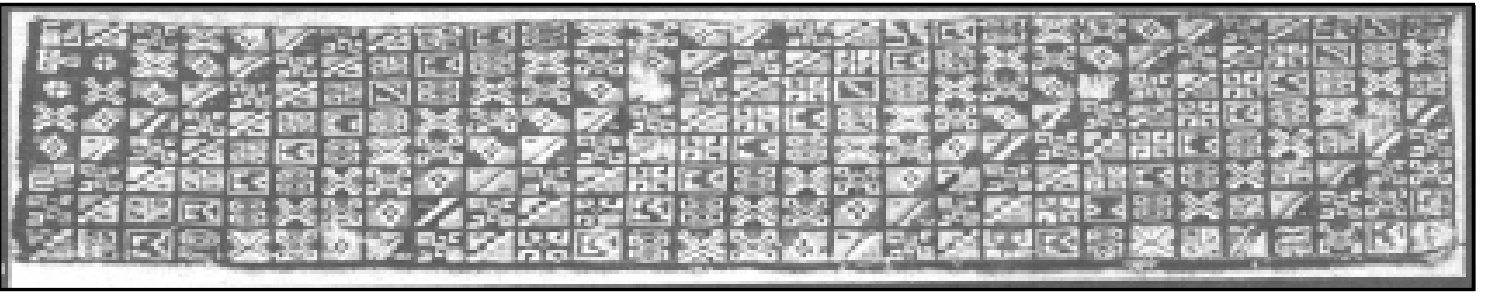

Figura 6. MAM 14636. 
por una doble tira de tocapus y en la parte inferior por bandas con motivos geométricos (grecas dobles inscritas en cuadrados y cruces rematadas por grecas). Despliega una amplia gama de colores y procede de Pachacamac (Ramos y Blasco 1980: 189, lám. XLIII y lám. XLIV, fig. A).

\section{Museo Etnológico (Barcelona)}

Este Museo tiene su origen en los pabellones del denominado Pueblo Español, que se construyeron con motivo de la Exposición Internacional de Barcelona de 1929, y que debían tener continuidad en el Museo de Artes e Industrias Populares.

Sin embargo, por distintas causas el proyecto originario no prosperó hasta 1940 y el nuevo edificio se inauguró en junio de 1942, con el nombre de Museo Etnológico y Colonial. En 1948 el Museo se reorganizó contando con dos secciones: la exótica y la hispánica, ubicadas en el Pabellón de La Rosaleda y en el Pueblo Español, respectivamente.

Finalmente, en 1972 se construyó cerca del Palacete Albéniz, residencia de los Reyes durante sus estancias en Barcelona, un nuevo edificio -destinado únicamente a ser el Museo Etnológico- cuyo fondo fue creciendo gracias a las adquisiciones que realizó el Ayuntamiento de Barcelona como propietario del mismo y a las donaciones de particulares.

De los 52 textiles andinos que posee el Museo, son en su gran mayoría fragmentos del Período Intermedio Tardío (Solanilla 1993: 55-62). A Nazca corresponden tres, dos de los cuales son fragmentos de cordón de dos hondas y el tercero es una honda completa decorada con motivos geométricos. A Tiahuanaco-Huari se asigna una tira decorada con motivos zoomorfos (monos y serpientes). A Chancay corresponden 26, a Chimú 10 y a ChimúChancay 12 , nueve agujas de tejer y tres fragmentos de dos bolsas y una tira que por su decoración podrían pertenecer a una o a la otra cultura. Finalmente al Período Colonial corresponde un tejido rectangular completo de algodón y lana con decoraciones geométricas paralelas, principalmente a base de cuadrados verde claro y oscuro, negro y crudo de diferentes medidas sobre fondo granate.

De la Cultura Chancay hay una pieza ( ${ }^{\circ}$ Inv. 138758; Solanilla 1999: 92, fig. 40) hecha con técnica de reps, decorada con cinco figuras ictiomorfas separadas por estilizaciones geométricas de ban- das paralelas con una greca en el centro (Figura 8). Existe una pieza igual en el MAM (Ramos y Blasco 1980: 132-134, lám. XXVI, fig. B) en cuanto a técnica, procedencia y decoración, pero difieren las medidas (sólo de la urdimbre, midiendo la del MEB el doble) y la disposición de las figuras (las del MEB en horizontal y las del MAM en vertical). El mismo tipo de textil lo encontramos en el CDMT ( $\mathrm{n}^{\circ}$ Inv. 99), pero en este caso la figura central es la de un felino (Solanilla (1999: 144, fig. 79).

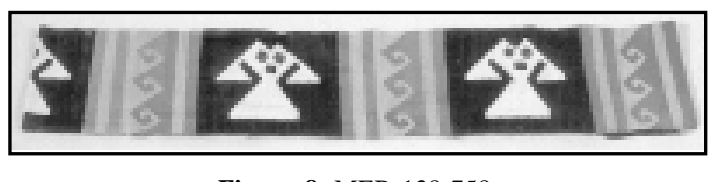

Figura 8. MEB 138-758.

Hay varias piezas ( ${ }^{\circ}$ Inv. 16-134 a y b; 138-753) decoradas con el típico diseño de pájaros en fila (Figuras 9 y 10), sobre fondo amarillo, todos en

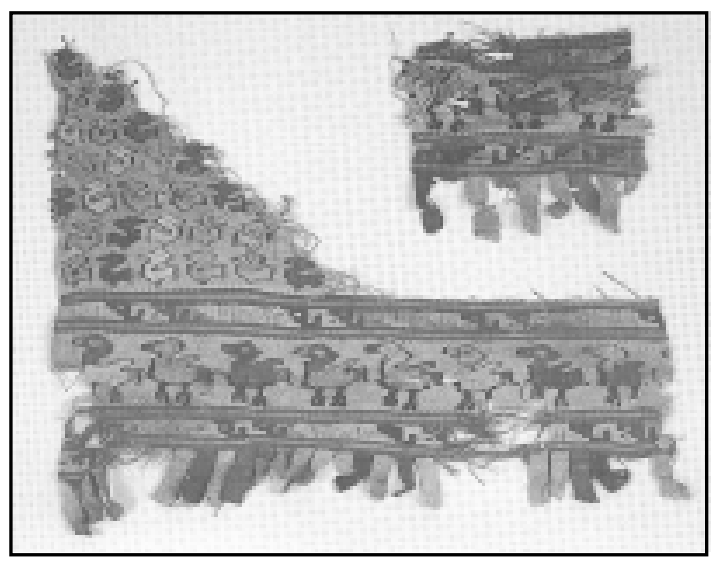

Figura 9. MEB 16-134, a y b.

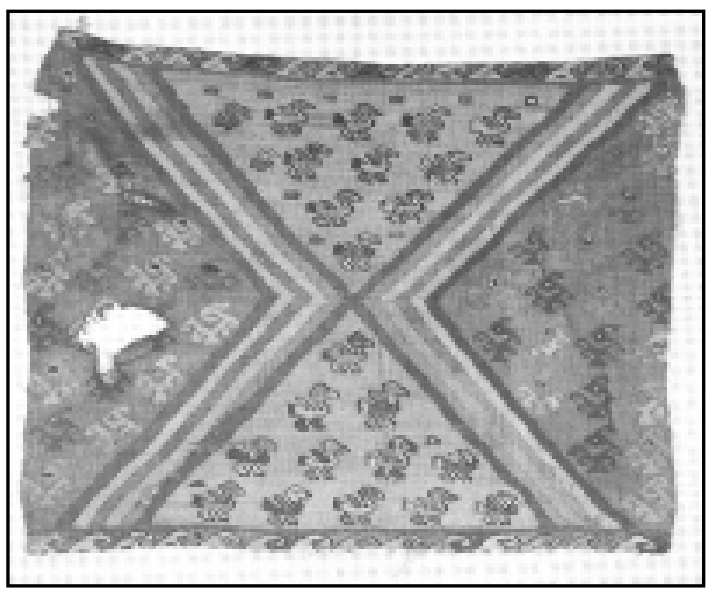

Figura 10. MEB 138-753 
la misma dirección (Solanilla 1999: 96, fig. 43 y pág. 108, fig. 49) que tiene paralelos en muchos museos, como por ejemplo en el Museo Nacional de Cracovia ( $n^{\circ}$ Inv. XIX-443; Solanilla 2000: 188-189).

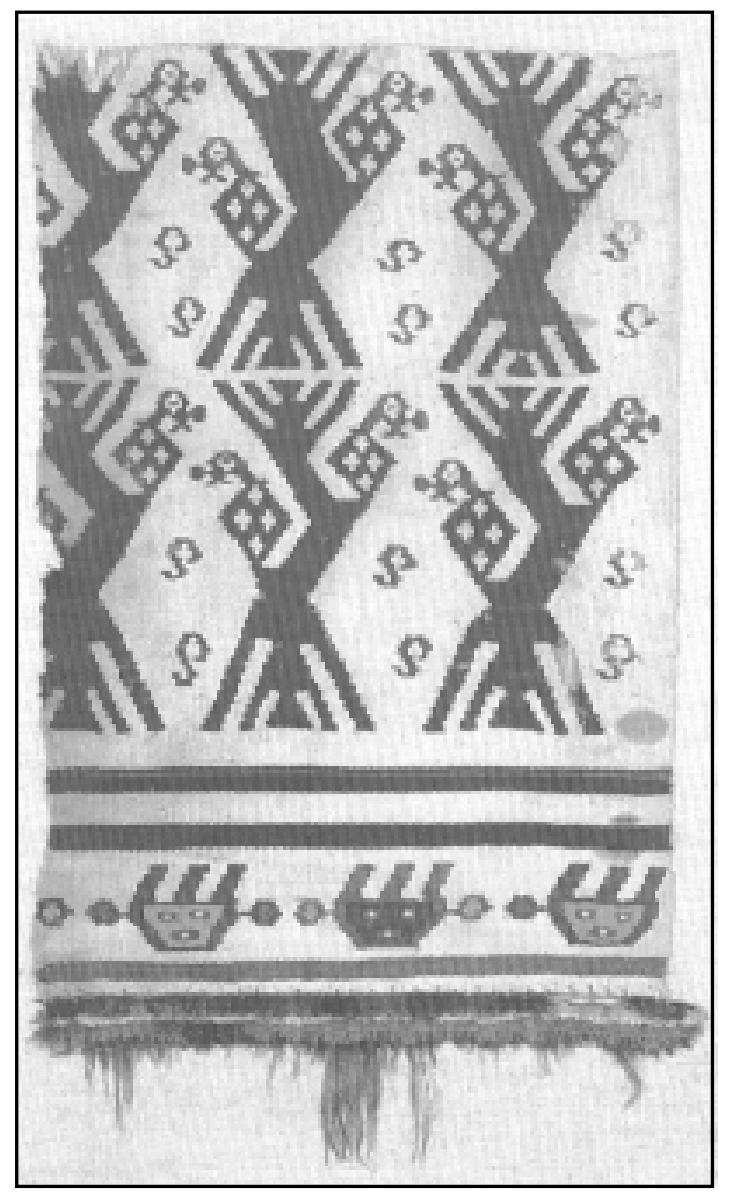

Figura 11. MEB 138-801.
De la Cultura Chimú destacamos un fragmento $\left(\mathrm{n}^{\circ}\right.$ Inv. 138-801) hecho con técnica de kilim (Solanilla (1999: 226, fig. 136) cuya decoración consiste en tres plantas a las que se acercan pájaros para picotear sus frutos. Se cierra la escena por su parte inferior por una tira de cabezas humanas muy geometrizadas y un fleco realizado con hilos muy finos. Este motivo es frecuente entre los tejidos de la época y se puede documentar fácilmente (Rowe 1984: 138, figs. 134 y 135).

\section{Museo Textil y de la Indumentaria (Barcelona)}

Fue fundado en 1982 con los fondos del antiguo Museo Textil, del de la Indumentaria, de la Colección Rocamora y del Encaje. La base del actual museo fueron las adquisiciones del legado Martorell que efectuó el Ayuntamiento en 1883, y las de la Junta de Museos de Barcelona. En la actualidad está instalado en un palacio medieval de la calle Montcada, en el corazón del Barrio Gótico de Barcelona.

Posee 39 piezas de época precolombina que llegaron al museo en dos momentos: el primero -que ya constaba en los fondos del antiguo Museo Textil, si bien no se conoce la fecha de entrada- estaba compuesto por 20 piezas de épocas diversas, pero de la misma procedencia: Perú prehispánico. Y el segundo, que tiene el mismo origen, se compone de 18 piezas pertenecientes al Período Intermedio Tardío. Esta colección entró al Museo el 17 de marzo de 1969 gracias a la compra que se realizó cuando el Sr. Juan Ainaud era director del Museo de Arte de Cataluña. Han sido culturalmente asignados, uno a Paracas Necrópolis, dos a Nazca, tres a Huari, uno a Ica, nueve a Chancay y 18 a Chimú (Solanilla 1993: 63-67 y 1999).

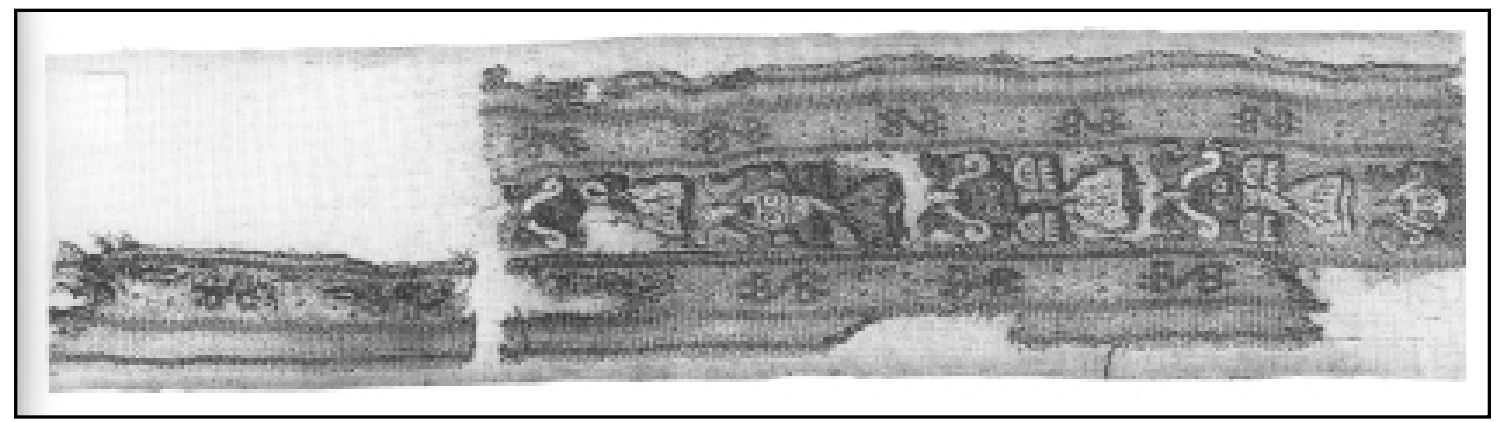

Figura 12. MTIB 28302. 


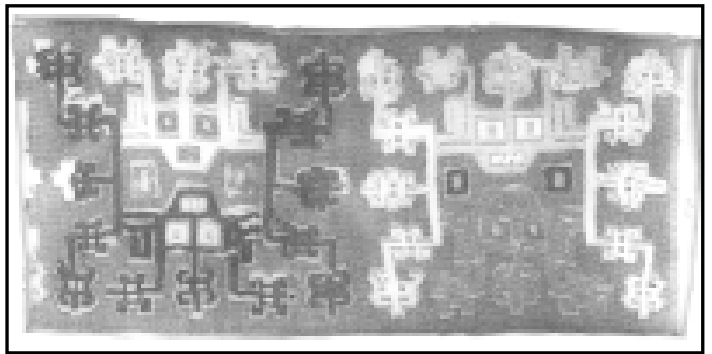

Figura 13. MTIB 28311.

De entre estas piezas destacamos dos de la Cultura Nazca ( $\mathrm{n}^{\mathrm{o}}$ Inv. 28302): una corresponde a un fragmento de tira hecha con la técnica de bordado a la aguja (Solanilla 1999: 24, fig. 1), en el que aparece un vencejo visto desde arriba (Figura 12), que está documentado por Sawyer (1997: 130, fig. 98) como proveniente de la tumba $\mathrm{n}^{\circ} 6$ de la necrópolis de Cabildo en la Costa Sur. El otro fragmento de esta cultura ( $\mathrm{n}^{\circ}$ Inv. 28311) está hecho en tapicería con técnica de kilim (Figura 13) y su decoración representa dos cabezas humanas afrontadas, muy geometrizadas, con múltiples apéndices hacia todos los lados (Solanilla 1999: 44, fig. 13). D'Harcourt (1962: 190, lám. 4; y 193, lám. 7) la documenta muy bien.

Una de las piezas Ica-Chincha con influencia Huari ( $\mathrm{n}^{\circ}$ Inv. 28306; Solanilla 1999: 60, fig. 21) es una tira de $11 \mathrm{~cm}$ de trama, hecha con técnica de reps, que está terminada de manera diferente en cada uno de sus extremos (Figura 14); tiene seis grupos de diseños totalmente geometrizados, dos

Figura 14. MTIB 28306. de los cuales representan al Señor de los Báculos. Su paralelo idéntico se ha de ir a buscar al Perú, al yacimiento de Socos en el valle del Chillón correspondiente a la época 2 del Horizonte Medio coincidente con la expansión Huari (IslaGuerrero 1987: 27-28, fig. 12). Se trata de una banda de un tocado procedente del cementerio del Complejo Macas, hecha con técnica de tapiz, con el mismo motivo decorativo.

Una de las piezas Huari ( ${ }^{\circ}$ Inv. 28310; Solanilla 1999: 52, fig. 17) hecha con técnica de tapiz, tiene una excelente decoración geométrica de la que

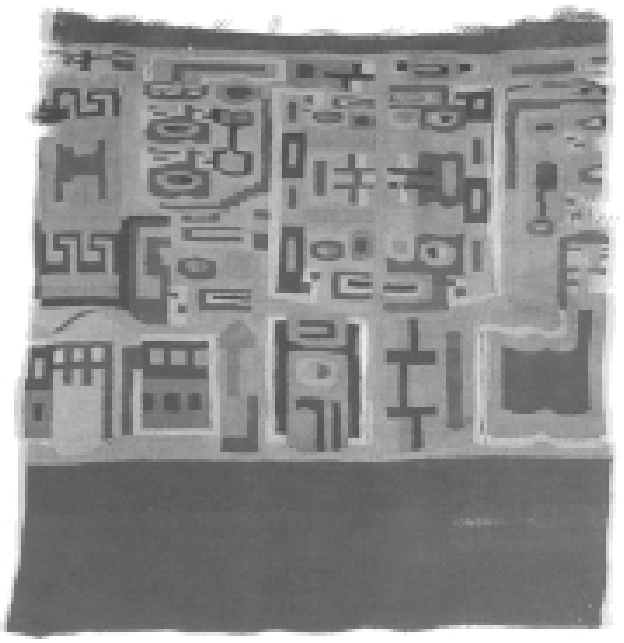

Figura 15 (arriba). MTIB 28310.

destacan dos cabezas afrontadas de perfil, enmarcada por bandas granates lisas (Figura 15).

Finalmente hay que destacar que un fragmento Chancay (n Inv. 28318) de algodón pintado, que representa una tira ancha de aves bicéfalas y debajo unas bandas paralelas y una greca (Solanilla 1999: 120, fig. 56), tiene su correspondiente en el MAM (Ramos y Blasco 1980: 165, lám. XXXV, $\mathrm{G})$ : coinciden medidas, tipo de tejido y decoración. Procede del valle del Supe.

El Museo posee un taller de restauración propio, unos almacenes que reúnen todas las condiciones necesarias para el buen mantenimiento de las piezas y una excelente biblioteca. También es de interés hacer constar, por la belleza del lugar donde se encuentra, que a la entrada del palacete hay un delicioso patio donde se halla instalado un agradable café-restaurante. 


\section{Centre de Documentació i Museu Tèxtil (Terrassa)}

La sede actual se inauguró el 17 de abril de 1971 como Museu Tèxtil de Terrassa, pero ya desde febrero de 1946 el Sr. Biosca i Torres creó un Museo Textil, antecedente del actual y producto de su afán coleccionista de textiles antiguos de gran calidad que duró muchos años. Más adelante, esta colección se incrementó con aportes de corporaciones industriales textiles. Se creó un Patronato en 1953, y en 1960 se cedió a la ciudad. Al cabo de tres años se convirtió en un museo provincial, lo que permitió enriquecerlo con la colección Viñas de Barcelona. A principios de 1981 el Patronato se disolvió y sus colecciones pasaron a depender de la Diputación de Barcelona. A partir de este momento pasó a llamarse Museu Tèxtil, hasta que con motivo de la última reorganización de los museos catalanes ha pasado a adoptar la denominación actual.

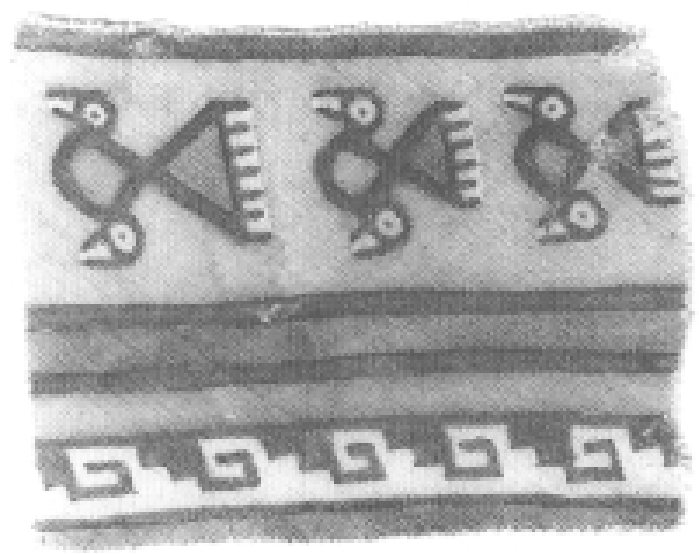

Figura 16. MTIB 28318.

El CDMT conserva en sus colecciones permanentes más de 15.000 piezas, entre las que es posible encontrar desde tejidos e indumentaria y accesorios hasta maquinaria y utillaje originarios de todo el mundo y de muy amplia cronología. ${ }^{2}$

La colección de textiles precolombinos consta de 55 piezas - producto de compra o de donaciones de particulares-, principalmente del Período In-

2 Es posible acceder a esta información a través de la página web del museo: www.cdmt.es termedio Tardío. Existen 38 de la Cultura Chancay y siete de Chimú, pero también hay seis piezas Paracas Necrópolis, dos de la Cultura Nazca y dos Inca (Solanilla 1993: 94-98). De entre las piezas Paracas, destaca un fragmento de manto (Solanilla 1999: 34, fig. 7) en el que se observan tres figuras iguales $\left(n^{\circ} 8039\right)$ : la de un personaje vestido con una túnica amplia que le llega hasta los muslos, con adornos en muñecas y tobillos, y en la cabeza una gran bigotera (Figura 17). En el hombro derecho lleva una máscara, y en el izquierdo nace una banda dentada, rematada por una cabeza. La misma decoración bordada, colores y textura la encontramos en una pieza del MAM (Solanilla 1999: 34, fig. 7). En este caso es más pequeña porque sólo tiene una figura. Otra pieza Paracas muy interesante es la ${ }^{\circ} 8034$, más estropeada que la anterior (Solanilla 1999: 34, fig. 7), cuya decoración también bordada representa una serie de personajes que parecen llevar una esclavina sobre el taparrabos y un gran tocado de plumas en la cabeza (Figura 18), en la mano derecha una cabeza trofeo y en la izquierda un báculo. Hay otra muy parecida en el Museo Nacional de Antropología y Arqueología de Lima (Lavalle y Lang 1980: 53) en la que tan sólo difiere el tocado, el que, aunque también es de plumas, es algo distinto al primero.

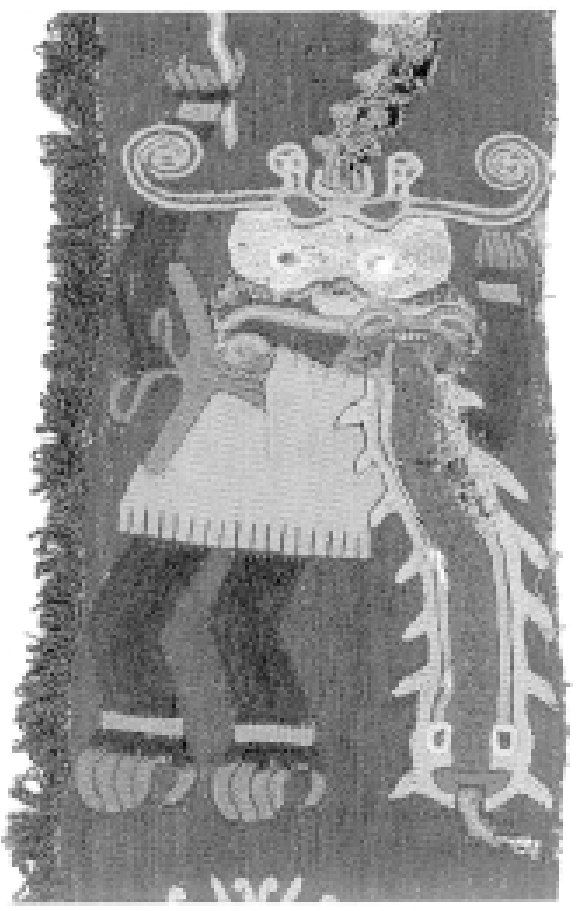

Figura 17. MTIB 8039. 


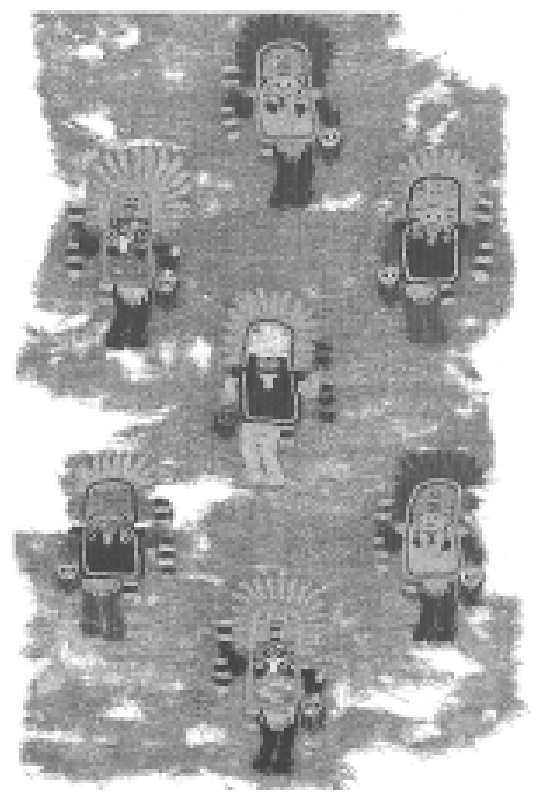

Figura 18. MTIB 8034.

De la Cultura Nazca hay un fragmento ( $\mathrm{n}^{\circ} 3911$ ) que está decorado con plumas de diversos colores que forman bandas paralelas (Figura 19). Posiblemente se trata de una chuspa abierta (Solanilla (1999: 42, fig. 12).

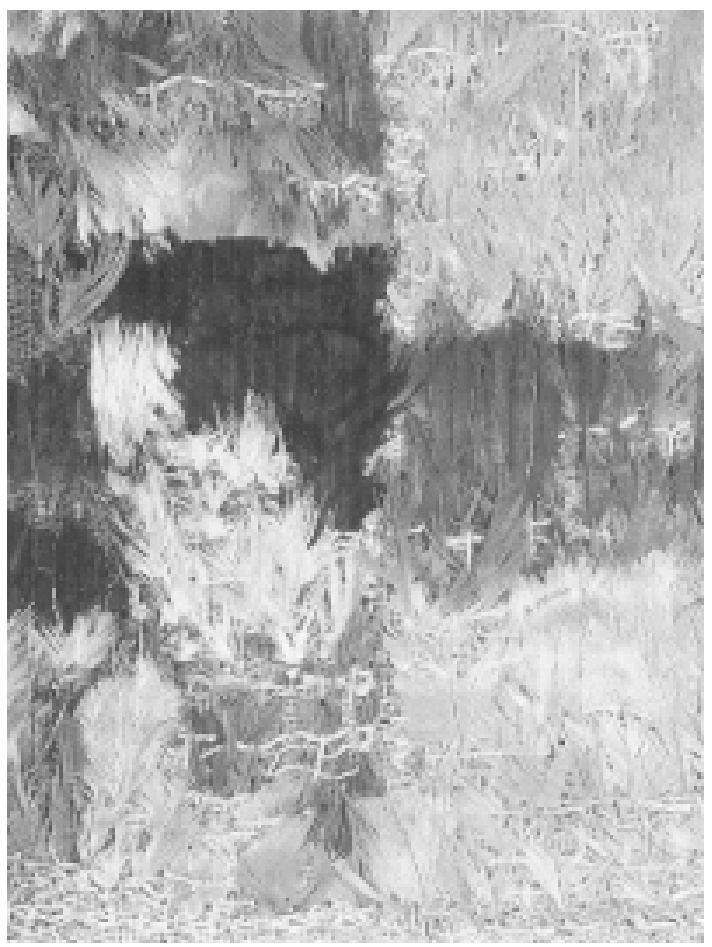

Figura 19. MTIB 3911.
De la Cultura Chancay hay numerosos fragmentos, como se ha dicho más arriba, de entre los que se pueden destacar: una gasa completa $\left(\mathrm{n}^{\circ} 3912\right.$; Solanilla 1999: 166, fig.93) de colores crudo y marrón medio decorada con rombos entrelazados en diagonal (Figura 20), y un fragmento de tapiz $\left(\mathrm{n}^{\circ}\right.$ 8043; Solanilla 1999: 178, fig.100) donde se destacan las figuras de felinos alternadas con grecas, todas ellas en diagonal hechas con vivos colores (Figura 21).

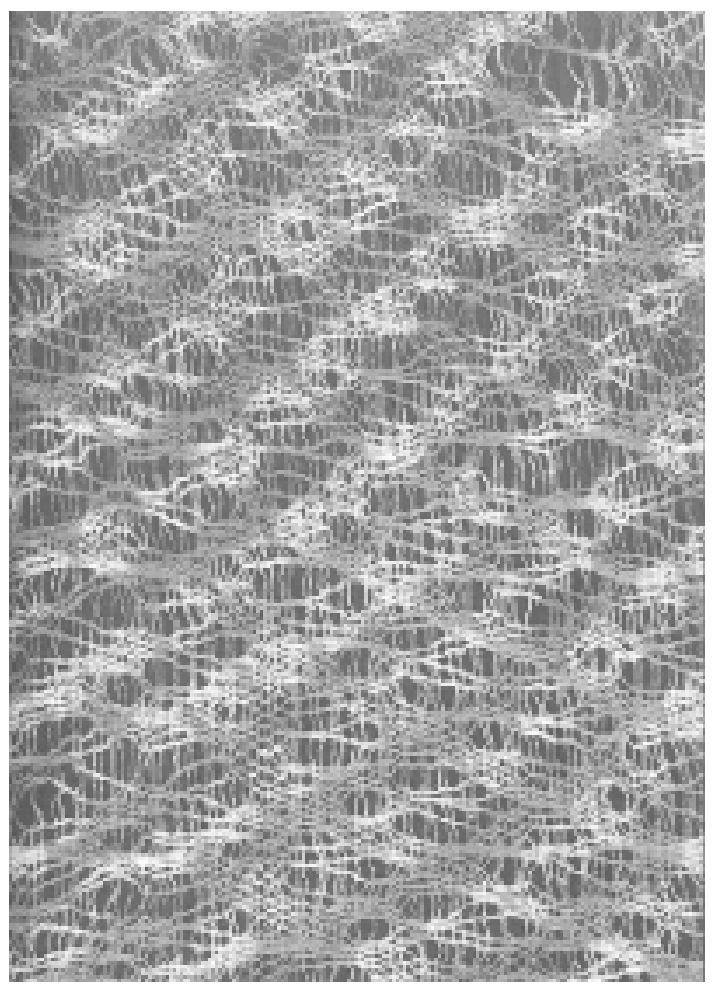

Figura 20. CDMT 3912.

Por último, de la Cultura Inca destaca un bello ejemplar (2573) de tejido decorado con tocapus (Figura 22) que posiblemente fue un uncu (Solanilla 1999: 254, fig.157) ya que constaba de dos partes cosidas por el centro. Su paralelo se encuentra también en el Museo NAA de Lima (Lavalle y Lang 1980: 173).

Los textiles están bien restaurados y forman una colección que está totalmente documentada en el banco de imágenes textiles IMATEX propio del Centro (Carbonell y Saladrigas 2000: 66-73).

Este banco de datos es un servicio que el CDMT pone a disposición de las personas que estén inte- 


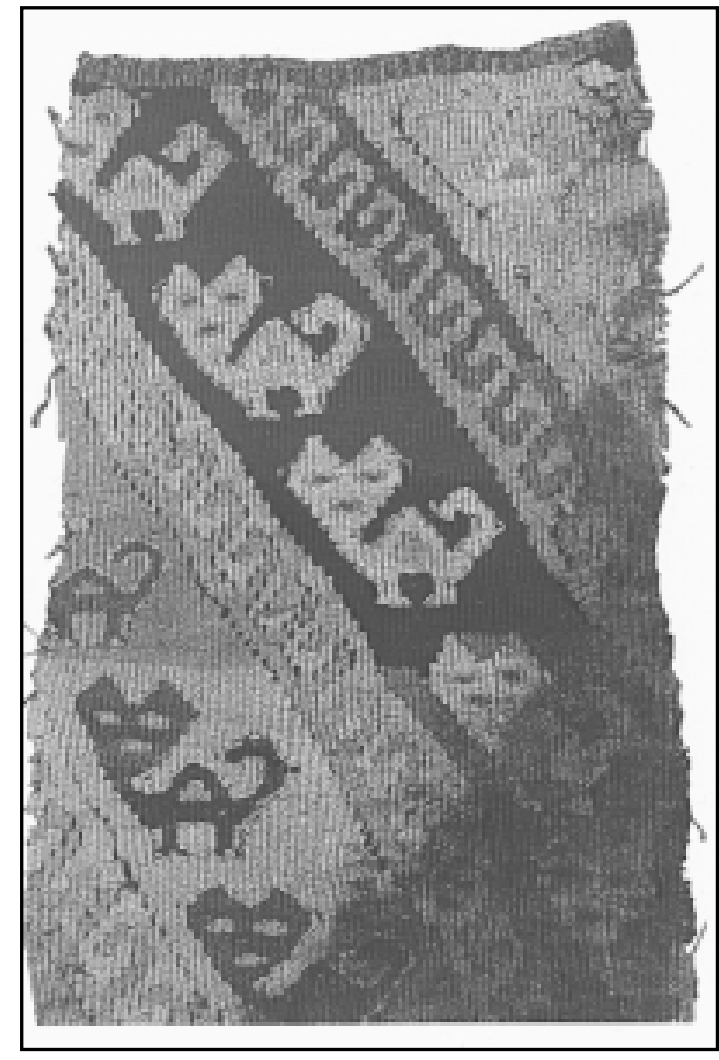

Figura 21. CDMT 8043.

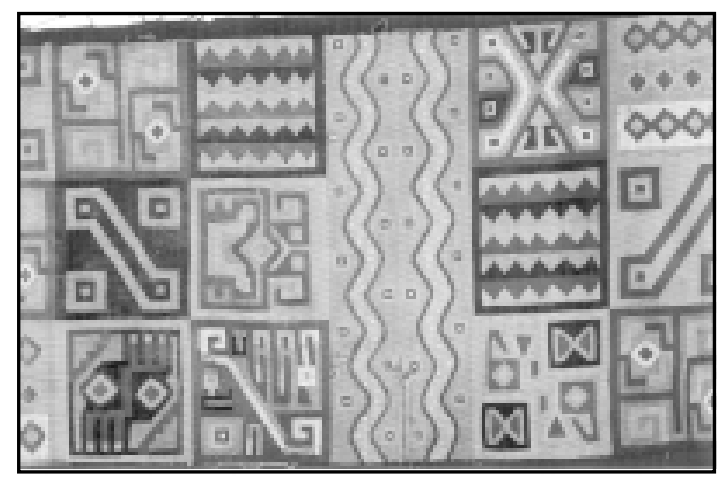

Figura 22. CDMT 2573.

resadas en acceder por vía telemática a las colecciones de tejidos y demás colecciones del fondo. Se trata de un sistema de archivo informático con imágenes y datos de las piezas, de amplio y variado contenido: en él se pueden encontrar tejidos de seda, de lana y de otros materiales, motivos orientales, geométricos, étnicos, florales, telas estampadas, vestidos, casacas, chalecos, medias, muestrarios de bordados, de corbatería, etc. $\mathrm{Su}$ difusión telemática permite la consulta a partir de un sistema de búsqueda basado en una serie de parámetros: materiales, técnicas, cronología, diseños, destino de uso, etc. El acceso a los datos y la visualización de las imágenes en tamaño estándar es gratuito. La visualización de las imágenes en tamaño ampliado es de pago.

\section{Museos locales}

Además de los museos mencionados, sin duda los más importantes, existe un grupo de museos locales catalanes que poseen pequeñas colecciones en cuanto a número pero no en lo que a su interés se refiere: entre estos el Museo Episcopal de Vic posee 12 piezas, el Museo Darder de Historia Natural de Banyoles cuenta con 11, el Museo Víctor Balaguer de Vilanova i la Geltrú, con seis, y el Museo Barbier Mueller de Barcelona con nueve. $^{3}$

Estas colecciones precolombinas de los museos locales son producto de las donaciones de los "indianos", es decir, los catalanes que durante los siglos XVIII y XIX fueron a "hacer las Américas" y a cuyo regreso a la patria al final de sus vidas legaron a los museos de sus respectivas villas todo aquello que habían traído consigo.

Quisiera hacer mención especial de las siguientes piezas: en el Museo Episcopal de Vic hay una interesante pieza Tiahuanaco-Huari ( ${ }^{\circ} 17156$; Solanilla 1999: 54, fig. 18) que consiste en un trozo de tira en la que con técnica de tapiz se ha representado una serpiente con doble cabeza y terribles fauces (Figura 23). En el Museo de América existe otro fragmento con la misma decoración en uno de sus extremos, que procede de Nazca (Ramos y Blasco 1980: 73, lám. X, H).

En el Museo Darder de Historia Natural de Banyoles se conserva la única momia andina que hay en los museos públicos de España. Es la pieza no 1003 (Solanilla 1999: 72, fig. 26). No está muy bien conservada, pero todavía se aprecian restos de tejido de una túnica de color claro con ribetes en las mangas y la cintura; de una tira alrededor del cuello; y de un turbante del que se pueden ver sus cabellos oscuros (Figura 24).

\footnotetext{
Véase Solanilla (1993) en lo que se refiere a las respectivas ubicaciones y contenido, y Solanilla (1999) en lo que se refiere en concreto a sus colecciones textiles.
} 


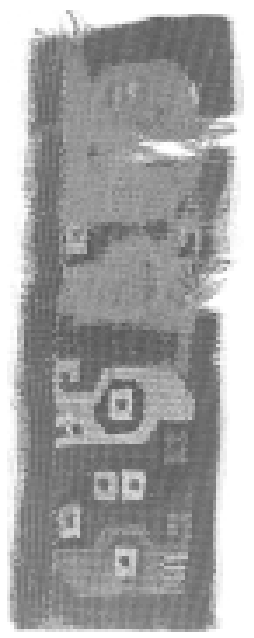

Figura 23. MEV 17156.

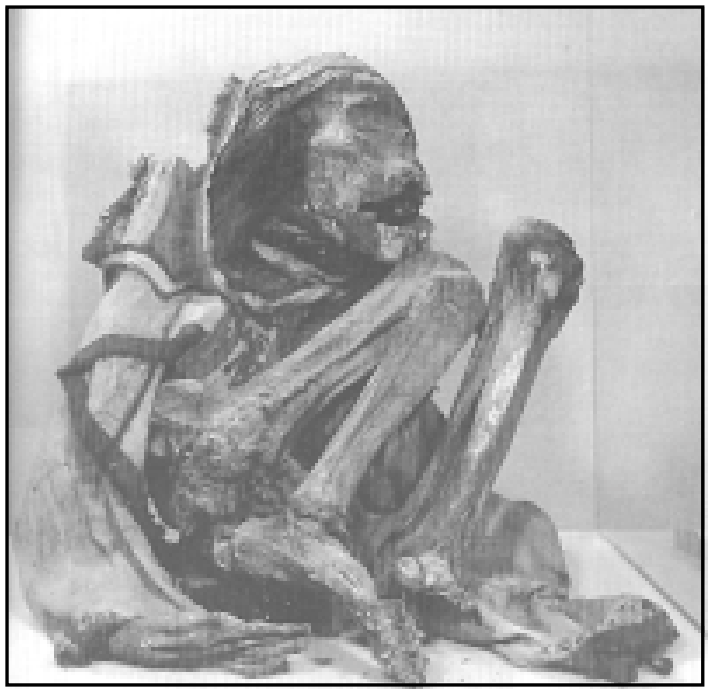

Figura 24. MDHN 1003.

En el Museo Víctor Balaguer de Vilanova i la Geltrú se conservan, entre otras, dos pequeñas bolsitas ( ${ }^{\circ}$ s 4067 y 4068 ; Solanilla 1999: 56, figs. 19 y 20) que por un lado están decoradas con finas líneas horizontales paralelas de color crudo sobre fondo azul-gris, y por el otro asemejan un rostro muy geometrizado (Figura 25). En el Museo de Módena también hay unos ejemplares iguales que se han clasificado como Moche-Huari procedentes de la necrópolis de Ancón y estaban hechos de tejido doble (Desrosiers y Pulini 1992: 126, figs. 31 y 32 ).

Finalmente, del Museo Barbier Mueller de Barcelona destacaría dos tejidos completos y muy

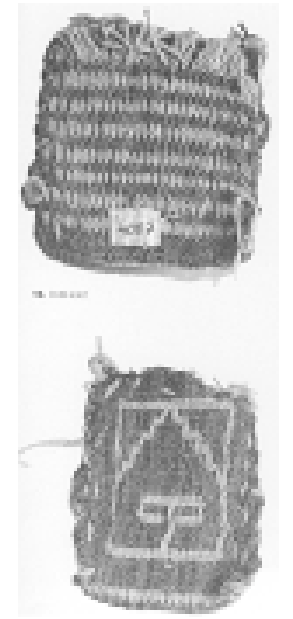

Figura 25. BMB 4067-4068.

bien conservados. El n ${ }^{\circ}$ 532-77 (Solanilla, en prensa) que es una pieza rectangular de algodón azul oscuro y que tiene una tira hecha con la técnica de bordado a la aguja cuyo motivo decorativo son series de colibríes que picotean flores de vivos colores (Figura 26). Procede de la Costa Sur y corresponde a la Cultura Nazca. El otro tejido es el иnси $\mathrm{n}^{\circ}$ 532-22 (Solanilla, en prensa) con decoración pintada y dos motivos diferentes: por un lado son unas series de circunferencias con punto central colocadas en 10 hileras paralelas, y por el otro, son ocho hileras paralelas de plumas estilizadas (Figura 27). Reiss y Stübel (1880-87: lám. 39) presentan en su publicación una pieza casi idéntica con la misma decoración de plumas estilizadas, que también es un uncu sin mangas.

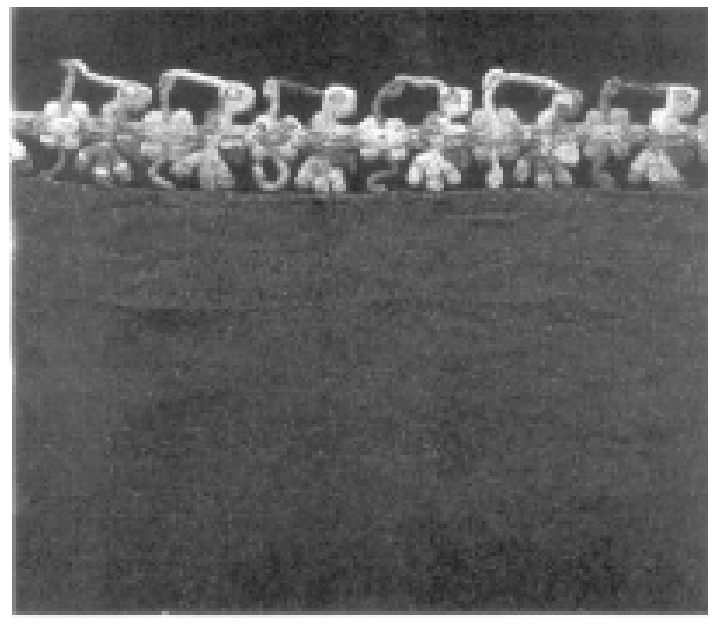

Figura 26. MBM 532-77. 


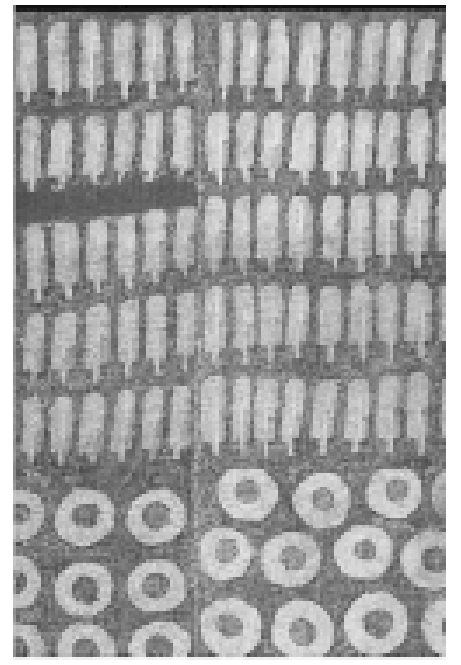

Figura 27. MBM 532-22.

Los dos ejemplares proceden de la Costa Central y corresponden a la Cultura Chancay.

Agradecimientos En primer lugar quisiera dar las gracias muy sinceramente a todas las personas de los museos en los que he investigado, quienes me han facilitado mucho el trabajo de recogida de datos sobre las piezas y me han proporcionado la documentación gráfica: Dra. Paz Cabello, Directora del Museo de América de Madrid; Dra. Carme Fauría, Directora del Museo Etnológico de Barcelona; Sra. Rosa M. Martín, Directora del Museu Tèxtil i de la Indumentària de Barcelona; Sra. Eulàlia Morral, Directora del Centre de Documentació i Museu Tèxtil de Terrassa; Mn. Gros, Director del Museu Episcopal de Vic; Sra. Georgina Gratacós, Directora del Museo Darder de Historia Natural de Banyoles; Sra. Montserrat Alós, administrativa del Museo Víctor Balaguer de Vilanova i la Geltrú; y Sra. Anna Casas, Directora del Museo Barbier Mueller de Barcelona.

Y en segundo lugar a la arqueóloga y colega Carolina Agüero del Museo R. P. Gustavo Le Paige s. j. de San Pedro de Atacama, por su invitación a participar en este número de la revista Estudios Atacameños, que espero sirva para dar a conocer en esas latitudes unos materiales que en su día marcharon a España provenientes del Area Andina.

\section{REFERENCIAS CITADAS}

CABELLO, P., 1989. Coleccionismo americano indígena en la España del siglo XVIII. Ediciones Cultura Hispánica, Instituto de Cooperación Iberoamericana, Madrid.

- 1994. El Museo de América. Ministerio de Cultura, Dirección General de Bellas Artes, Madrid.

CARBONELL, S. y SALADRIGAS, S., 2000. Colecciones on-line. Actas de la I Jornada Internacional sobre Textiles Precolombinos, V. Solanilla (Ed.), pp. 66-73, Universidad Autónoma de Barcelona, Barcelona.

CUESTA DOMINGO, M., 1980. Arqueología andina: Perú. Ministerio de Cultura, Madrid.

DESROSIERS, S. y PULINI, I., 1992. Tessuti precolombiani. Paninni Ed., Módena.

D’HARCOURT, R., 1962. Textiles of Ancient Peru and their techniques. University of Washington Press, Seattle.

ECIJA, A. y A. VERDE, 2000. La colección de textiles andinos precolombinos y coloniales del Museo de América de Madrid. Actas de la I Jornada Internacional sobre Textiles Precolombinos, V. Solanilla (Ed.), pp. 57-65, Universidad Autónoma de Barcelona, Barcelona.
ISLA, E. y D. GUERRERO, 1987. Socos: Un sitio Wari en el valle del Chillón. Gaceta Arqueológica Andina 14: 23-28, Lima.

JANER, F., 1860 Ms. Historia, descripción y catálogo de las colecciones histórico-etnográficas, curiosidades diversas $y$ antigüedades conservadas en el Museo de Ciencias Naturales de Madrid. Museo de América, Madrid.

JIMENEZ, M. J., 2000. Los tejidos prehispánicos del Museo de América y la reconstrucción del pasado andino. Anales del Museo de América 8: 225-270, Madrid.

LAVALLE, J.A. de, y LANG, W., 1980. Arte precolombino: Arte textil y adornos. Banco de Crédito del Perú en la Cultura, Lima.

RAMOS, J. L. y M. C. BLASCO, 1980. Los tejidos prehispánicos del Area Central Andina en el Museo de América. Ministerio de Cultura, Madrid.

REISS, W. y STÜBEL, A., 1880-87. Das Totenfeld von Ancon in Perú. Ein Beitrag zur Kenntnis der Kultur und industrie des Inca-Reiches, 3 vols. Berlín.

ROWE, A. P., 1984. Costumes and featherwork of the Lords of Chimor. The Textile Museum, Washington D.C. 


\section{LAS COLECCIONES DE TEXTILES ANDINOS EN LOS MUSEOS DE ESPAÑA}

SAWYER, A., 1997. Early Nasca needlework. Primitive Arts, Ltd., Londres.

SOLANILLA, V., 1993. Col-leccions precolombines als museus de Catalunya. Generalitat de Catalunya, Comissió Amèrica i Catalunya 1992, Barcelona.

— 1999. Tèxtils precolombins de col-leccions públiques catalanes. Corpus Antiquitatum Americanensium, Institut d'Estudis Catalans, Barcelona.
2000. Textiles precolombinos de Cracovia. Corpus Antiquitatum Americanensium (Pologne II), Académie Polonaise des Sciences et des Lettres, Cracovia.

- En prensa. La colección de textiles del Museo BarbierMüller de Barcelona (España). Actas II Jornadas Internacionales sobre Textiles Precolombinos, V. Solanilla (Ed.), Universidad Autónoma de Barcelona, Barcelona. 